\title{
Effect of calcium and diltiazem on phenylhydrazine-induced oxidative injury in goat erythrocytes
}

\author{
Kaushik Das*, Jharna Bhattacharyya
}

Division of Cell Biology and Physiology, Indian Institute of Chemical Biology, Kolkata, India; *Corresponding Author: kaushik.17@gmail.com

Received 8 June 2010; revised 22 June 2010; accepted 7 July 2010.

\begin{abstract}
Lipid peroxidation, hemolysis and thiol contents were studied in intact goat erythrocytes exposed to phenylhydrazine. An increase in lipid peroxidation, hemolysis and thiol content was observed after phenylhydrazine treatment of erythrocyte. Extracellular $\mathrm{Ca}^{2+}$ potentiates the phenylhydrazine-induced lipid peroxidation and hemolysis of erythrocytes significantly. $\mathrm{Ca}^{2+}$ does not influence much the thiol content of phenylhydrazine treated erythrocytes. No effect of $\mathrm{Ca}^{2+}$ on control lipid peroxidation, hemolysis and thiol contents of erythrocytes was observed. Diltiazem and EDTA inhibited the increased responses of lipid peroxidation and hemolysis due to $\mathrm{Ca}^{2+}$. However the thiol content was not much influenced by either diltiazem or EDTA. The results suggest that oxidative damage of erythrocyte caused by phenyl hydrazine could be prevented by calcium channel antagonist, diltiazem, which may act as antioxidant also.
\end{abstract}

Keywords: $\mathrm{Ca}^{2+}$; Diltiazem; Erythrocyte; Free Radical; Lipid Peroxidation; Phenylhydrazine

\section{INTRODUCTION}

Phenylhydrazine (PHZ) and other oxygen generating systems cause elevation of lipid peroxidation level in erythrocytes [1]. PHZ through oxidative stress also altered methemoglobin level, catalase activity and turbidity of erythrocyte [1], which are typical biochemical markers of haemolytic anaemia. Oxidative stress is defined as structural and/or functional injury produced in tissues by the uncontrolled formation of pro-oxidant free radicals. Oxidative stress usually develops when pro-oxidant action of an inducer exceeds the anti-oxidant capacity of the cell-defence system, altering its homeostatic capacity. PHZ, in presence of haemoglobin autooxidizes to form hydrogen peroxide, which leads to hemolysis, resulting in severe haemolytic anaemia [2] and generates reactive oxygen species [3] among which hydroxyl radical, $\mathrm{OH} \cdot[4]$ is highly reactive and initiates the peroxidation of unsaturated fatty acids in endogenous phospholipids. Oxidative stress due to overproduction of reactive species plays a significant role in the pathogenesis of various diseases and involves numerous mechanisms. All biological molecules are prone to free radical attack. Lipid peroxidation is a chain reaction, involving numerous biproducts caused by free radical damage.

The modulators involved in the production of haemolytic anaemia caused by PHZ are not fully understood. $\mathrm{Ca}^{2+}$ has been implicated as an important contributory factor to cell damage caused by the resultant effect of oxidative stress in several diseases [5]. $\mathrm{Ca}^{2+}$ influx has been reported to increase in pathophysiological conditions where $\mathrm{Ca}^{2+}$-channel blockers have got an important regulatory role [5]. In some studies the role of lipid peroxidation in cell death has implicated a concurrent involvement of $\mathrm{Ca}^{2+}$. The component, which increases $\mathrm{Ca}^{2+}$ influx-increases lipid production biproducts also. A number of experimental systems have been used to examine the interaction between lipid peroxidation and $\mathrm{Ca}^{2+}$ as mediators of functional membrane damage [6]. Voltage dependant calcium channels (VDCCs) play a critical role in the regulation of levels of intracellular $\mathrm{Ca}^{2+}$ and thereby control an array of physiological processes in cells and VDCCs functioning could be prevented by using calcium channel blockers [7]. Thus regulating $\mathrm{Ca}^{2+}$ influx through VDCCs by using calcium channel blockers, which act as antioxidants as well, could have some impact on the calcium mediated lipid peroxidation in several disease conditions.

The present study is an attempt to study the role of calcium and calcium channel blocker diltiazem, on lipid 
peroxidation induced by PHZ in erythrocytes. Since in haemolytic diseases membrane fragility is altered, the hemolysis as well as the thiol content of erythrocytes was also studied under the same experimental condition.

\section{MATERIALS AND METHODS}

All the experiments were performed using goat blood, which was collected from acid-citrate dextrose solution. The packed erythrocytes were isolated by centrifugation at $3000 \mathrm{~g}$ for $10 \mathrm{~min}$ at $4^{\circ} \mathrm{C}$. The plasma and buffy coat were removed by aspiration and the erythrocytes thus obtained were washed thrice and suspended in $0.9 \%$ $\mathrm{NaCl}$ solution [1].

Incubation of erythrocytes with calcium and calcium channel blocker - The incubation medium contained 10 $\mathrm{mM}$ sodium phosphate buffer (pH 7.4), $1 \mathrm{mM}$ PHZ, 2 $\mathrm{mM} \mathrm{Ca}{ }^{2+}, 20 \mu \mathrm{M}$ diltiazem/2 mM EDTA, $10 \mathrm{mM}$ Glucose and erythrocyte suspension was incubated at $37^{\circ} \mathrm{C}$ in a shaker water bath. At the end of the incubation the cells were collected by centrifugation, washed and lysed with $5 \mathrm{mM}$ sodium phosphate buffer $(\mathrm{pH} 8.0,1: 10 \mathrm{w} / \mathrm{v})$ and hemolysate were obtained by centrifugation at $10,000 \mathrm{x} g$ for $1 \mathrm{hr}$. The resulting supernatant was taken for experimental purposes.

Lipid peroxidation: Lipid peroxidation of hemolysates from both control and treated erythrocytes were determined by malondialdehyde (MDA) estimation as done previously [1]. Thio barbituric acid (TBA) reactant products were estimated by MDA liberated by the breakdown of polyunsaturated fatty acids and expressed as MD$\mathrm{A} / \mathrm{mg}$ protein by calculating the extinction co-efficient of MDA [8].

Hemolysis: After incubation of erythrocytes with the other ingredients, equal volume of saline was added to the incubation mixture and centrifuged at $2000 \mathrm{rpm}$ for $10 \mathrm{~min}$ and the supernatants were taken for absorbancy at $540 \mathrm{~nm}$ against reagent blank [9]. During incubation same amount of packed cell proteins were added to each tube.

Thiol estimation: Thiol content of the hemolysates was estimated according to Owens and Belcher [10]. Trichloroacetic acid (TCA) was used instead of metaphosphoric acid for protein precipitation. $0.5 \mathrm{ml}$ of $5 \%$ TCA filtered extract of each sample was added to a mixture of $1.5 \mathrm{ml}$ of $0.5 \mathrm{M}$ potassium phosphate buffer, $\mathrm{pH} 8.0$ and $0.03 \mathrm{ml}$ of dithionitrobenzene reagent. The optical density was measured at $412 \mathrm{~nm}$ after $3 \mathrm{~min}$ and compared with the standards made with reduced glutathione dissolved in $0.5 \%$ TCA. Values are expressed as nmoles of thiols liberated per mg protein.

Protein measurement: The protein content of the samples was determined according to the method of Bradford [11].
Statistical analysis: Statistical significance was measured as mean \pm SD and Student's t-test was used for determination of statistical significance.

\section{RESULTS AND DISCUSSION}

Goat erythrocytes when incubated with PHZ (1 mM), a strong oxidant, caused an elevation $(\mathrm{P}<0.001)$ of lipid peroxidation (Figure 1). The increase was about 126\% over control values. Additionally, in presence of divalent cation $\mathrm{Ca}^{2+}(2 \mathrm{mM})$ there was further elevation of lipid peroxidation (Figure 1). Below the concentration of $2 \mathrm{mM}$ $\mathrm{Ca}^{2+}$ with $\mathrm{PHZ}$, any significant increase of lipid peroxidation could not be detected, hence in our further experiments $2 \mathrm{mM}$ concentration of $\mathrm{Ca}^{2+}$ was chosen as optimum. Diltiazem, a calcium channel antagonist, at $20 \mu \mathrm{M}$ antagonizes the action of calcium (Figure 1) and hence the elevated level of lipid peroxidation was suppressed by the addition of diltiazem $(\mathrm{P}<0.01$, compared to $\mathrm{PHZ}$ $(1 \mathrm{mM})+\mathrm{Ca}^{2+}(2 \mathrm{mM})$ treated group $)$. Similarly, addition of $2 \mathrm{mM}$ EDTA (equimolar concentration of $\mathrm{Ca}^{2+}$ ) to the incubation medium also caused inhibition of increased lipid peroxidation caused by $\mathrm{PHZ}(1 \mathrm{mM})+\mathrm{Ca}^{2+}(2 \mathrm{mM})$.

Like lipid peroxidation, the other criteria of $\mathrm{PHZ}$ action were to check the change of hemolysis pattern of erythrocyte. As shown in Figure 2, it is evident that the hemolysis of erythrocyte occurred significantly when incubated with PHZ (0.16 vs. 0.02). $\mathrm{Ca}^{2+}$ elevated the level further, diltiazem and EDTA suppressed the haemolysis values due to $\mathrm{PHZ}$ and $\mathrm{Ca}^{2+}$ (Figure 2).

The protein degradation product, the thiol content, was found to alter when erythrocytes were treated like before (Table 1). As shown in Table 1, when erythrocytes were

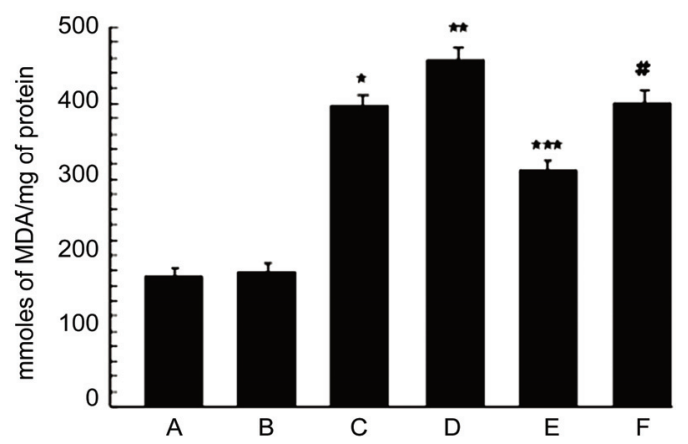

Figure 1. Effect of $\mathrm{Ca}^{2+}$ diltiazem and EDTA on PHZ-induced lipid peroxidation of erythrocytes. [A: Control erythrocytes without any treatment; B: Control erythrocytes with $2 \mathrm{mM} \mathrm{Ca}^{2+}$; C: $1 \mathrm{mM}$ PHZ-treated erythrocyte, $\mathrm{P}<0.001$ against $\mathrm{A}$; $\mathrm{D}: 1 \mathrm{mM} \mathrm{PHZ}+2 \mathrm{mM}$ $\mathrm{Ca}^{2+}, \mathrm{P}<0.001$ against $\mathrm{C}$; $\mathrm{E}: 1 \mathrm{mM} \mathrm{PHZ}+2 \mathrm{mM} \mathrm{Ca}^{2+}+$ $20 \mu \mathrm{m}$ diltiazem, $\mathrm{P}<0.01$ against $\mathrm{D} ; \mathrm{F}: 1 \mathrm{mM} \mathrm{PHZ}+2$ $\mathrm{mM} \mathrm{Ca}{ }^{2+}+2 \mathrm{mM}$ EDTA, $\mathrm{P}<0.05$ against $\mathrm{D}$. Values given are mean $\pm \mathrm{SD}$ of 6 different experiments]. $* \mathrm{P}<$ $0.001, * * \mathrm{P}<0.01, * * * \mathrm{P}<0.01, \# \mathrm{P}<0.05$. 


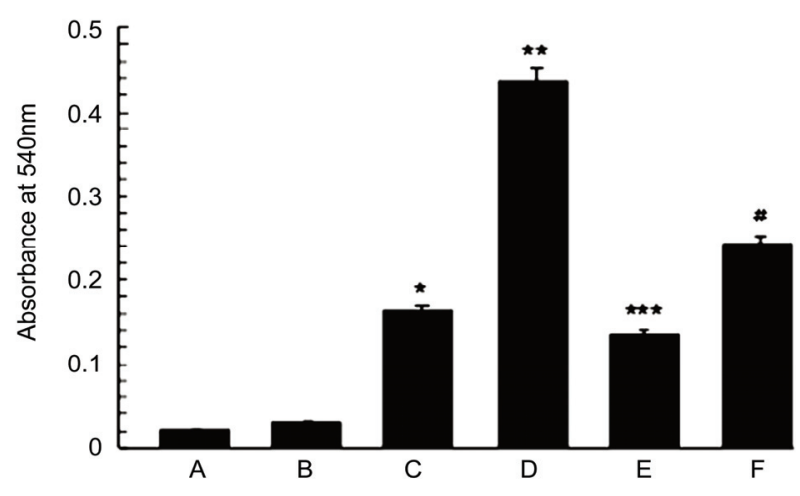

Figure 2. Effect of $\mathrm{Ca}^{2+}$, diltiazem and EDTA on PHZ-induced hemolysis of erythrocyte. [A: Control erythrocyte without any treatment; B: Control erythrocytes with $2 \mathrm{mM} \mathrm{Ca}^{2+}$; $\mathrm{C}: 1 \mathrm{mM}$ PHZ-treated erythrocyte, $\mathrm{P}<0.001$ against A; D: $1 \mathrm{mM} \mathrm{PHZ} \mathrm{+}$ $2 \mathrm{mM} \mathrm{Ca}^{2+}, \mathrm{P}<0.001$ against C; E: $1 \mathrm{mM} \mathrm{PHZ}+2 \mathrm{mM} \mathrm{Ca}^{2+}+$ $20 \mu \mathrm{M}$ diltiazem, $\mathrm{P}<0.01$ against $\mathrm{D} ; \mathrm{F}: 1 \mathrm{mM} \mathrm{PHZ}+2 \mathrm{mM}$ $\mathrm{Ca}^{2+}+2$ mM EDTA, $\mathrm{P}<0.05$ against $\mathrm{D}$. Values given are mean $\pm \mathrm{SD}$ of 6 different experiments]. ${ }^{*} \mathrm{P}<0.001, * * \mathrm{P}<$ $0.01, * * * \mathrm{P}<0.01$, \# $\mathrm{P}<0.05$.

Table 1. Effect of $\mathrm{Ca}^{2+}$ and diltiazem and EDTA on thiol content of PHZ treated erythrocyte.

[Values are means $\pm \mathrm{SD}$ of 6 different experiments]

\begin{tabular}{cc}
\hline System & $\begin{array}{c}\text { Thiol content } \\
\text { (n mol } / \mathrm{mg} \text { protein })\end{array}$ \\
\hline Control & $28.79 \pm 0.23$ \\
Control $+\mathrm{Ca}^{2+}(2 \mathrm{mM})$ & $27.55 \pm 0.22$ \\
$\mathrm{PHZ}(1 \mathrm{mM})$ & $32.00 \pm 0.18^{*}$ \\
$\mathrm{PHZ}(1 \mathrm{mM})+\mathrm{Ca}^{2+}(2 \mathrm{mM})+\operatorname{diltiazem}(20 \mu \mathrm{m})$ & $30.48 \pm 0.15^{* * *}$ \\
$\mathrm{PHZ}(1 \mathrm{mM})+\mathrm{Ca}^{2+}(2 \mathrm{mM})+$ EDTA $(2 \mathrm{mM})$ & $30.50 \pm 0.14^{\#}$ \\
\hline
\end{tabular}

${ }^{*} \mathrm{P}<0.001,{ }^{* *} \mathrm{P}<0.01,{ }^{* * *} \mathrm{P}<0.01,{ }^{*} \mathrm{P}<0.05$

treated with PHZ (1 mM) alone, the thiol content was increased and addition of $\mathrm{Ca}^{2+}(2 \mathrm{mM})$ to the system further enhanced the thiol level. In comparison to lipid peroxidation and hemolysis, the increment observed was less when thiol was measured from treated erythrocytes. Both diltiazem and EDTA were found to reduce the increased level of thiols in PHZ and $\mathrm{Ca}^{2+}$ treated erythrocytes (Table 1). Further we have confirmed our lipid peroxidation experiment using $\mathrm{Cu}^{2+}(0.2 \mathrm{mM})+$ Ascorbic acid ( $1 \mathrm{mM}$ ) system (Table 2). Results obtained showed that the changes observed were more or less similar in $\mathrm{Cu}^{2+}$-Ascorbate system as compared with PHZ.

The involvement of oxygen-derived free radicals and other oxidant species in numerous pathophysiological conditions helps to develop suitable systems to study their effects and also to assess the antioxidant activity of endo/exogenous compounds. To confirm the previous re- sults [1], the effect of modulators was evaluated on PHZ treated erythrocytes. An erythrocyte model was taken for lipid peroxidation, hemolysis and thiol content, where PHZ was chosen as oxidant and $\mathrm{Ca}^{2+}$, diltiazem and EDTA as modulators of PHZ mediated action. PHZ generally produces haemolytic anaemia in in vivo system. The present results indicate that the damaging effect due to PHZ on erythrocyte could be repeated in in vitro system also. $\mathrm{Ca}^{2+}$ could have an important role in the pathophysiology of sickling process. Sickle cells, which maintain an abnormally deformed shape, have three to seven times higher $\mathrm{Ca}^{2+}$ level as compared to normal red blood cells [12]. Interestingly the results have shown that $\mathrm{Ca}^{2+}$ enhanced the action of PHZ on lipid peroxidation and hemolysis mostly. These two criteria are often observed in anaemic condition. Lipid peroxidation, a marker of membrane function, as well as hemolysis is greatly altered when $\mathrm{Ca}^{2+}$ is added with $\mathrm{PHZ}$ to the incubation medium. $\mathrm{Ca}^{2+}$ alone without PHZ, on the other hand has got no significant effect on the criteria studied above.

Many of the mechanical properties of sickle cell membrane have been found to relate to high $\mathrm{Ca}^{2+}$ level [13]. Because of the role of $\mathrm{Ca}^{2+}$ in injurious processes, $\mathrm{Ca}^{2+}$ antagonists have been tested for reducing the detrimental consequences. In vitro studies on $\mathrm{Ca}^{2+}$ antagonists have been carried out by various workers [14] with the view to prevent the injurious effects of $\mathrm{Ca}^{2+}$ on erythrocytes. They concluded that these $\mathrm{Ca}^{2+}$ antagonists either singly or in combination might be useful in preventing vasoocclusive events. $\mathrm{Ca}$ channel antagonists were shown to act as antioxidant [15]. Calcium antagonists antioxidant potency correlated directly with the compound's relative affinity for the membrane lipid bilayer [16]. Similarly in

Table 2. Effect of $\mathrm{Ca}^{2+}$ diltiazem and EDTA on $\mathrm{Cu}^{2+}$-ascorbate ${ }^{\mathrm{a}}$-induced lipid peroxidation of erythrocytes.

[Values are means $\pm \mathrm{SD}$ of 6 different experiments]

\begin{tabular}{cc}
\hline System & $\begin{array}{c}\text { Lipid peroxidation } \\
(\mathrm{n} \mathrm{mol} / \mathrm{mg} \text { protein })\end{array}$ \\
\hline Control & $168.25 \pm 1.67$ \\
$\mathrm{Control}+\mathrm{Ca}^{2+}(2 \mathrm{mM})$ & $170.55 \pm 1.01$ \\
$\mathrm{Cu}^{2+}(0.2 \mathrm{mM})+$ Ascorbic acid $(1 \mathrm{mM})$ & $335.00 \pm 4.23^{*}$ \\
$\mathrm{Cu}^{2+}(0.2 \mathrm{mM})+$ Ascorbic acid $(1 \mathrm{mM})+$ & $398.65 \pm 3.67^{* *}$ \\
$\mathrm{Ca}^{2+}(2 \mathrm{mM})$ & \\
$\mathrm{Cu}^{2+}(0.2 \mathrm{mM})+$ Ascorbic acid $(1 \mathrm{mM})+$ & $305 \pm 2.67^{* * *}$ \\
$\mathrm{Ca}^{2+}(2 \mathrm{mM})+$ diltiazem $(20 \mu \mathrm{m})$ & $346 \pm 4.33^{\#}$ \\
$\mathrm{Cu}^{2+}(0.2 \mathrm{mM})+$ Ascorbic acid $(1 \mathrm{mM})+$ & \\
\hline${ }^{*} \mathrm{P}<0.001,{ }^{* *} \mathrm{P}<0.01,{ }^{* * *} \mathrm{P}<0.01,{ }^{*} \mathrm{P}<0.05$ & \\
${ }^{\mathrm{a}} \mathrm{Assay} \mathrm{system} \mathrm{was} \mathrm{followed} \mathrm{according} \mathrm{to} \mathrm{Halder,} \mathrm{J.} \mathrm{and} \mathrm{Bhaduri,} \mathrm{A.N.,}$ \\
$1998[3]$.
\end{tabular}


our studies the results have shown that micromolar concentration of $\mathrm{Ca}^{2+}$ antagonist, diltiazem, decreased the level of lipid peroxidation, hemolysis and thiol content of erythrocyte when treated with $\mathrm{PHZ}$ and $\mathrm{Ca}^{2+}$. Metal chelator EDTA, on the other hand was not found to be as effective as diltiazem in preventing these damaging processes.

Earlier reports [17] using erythrocyte as a model have shown increased erythrocytic protein degradation when erythrocytes were treated with PHZ. Therefore, it is expected that more the degradation, more thiol groups would be liberated. Practically this was found in the present experiments, where in vitro addition of PHZ plus $\mathrm{Ca}^{2+}$ caused increased SH level (though not to a greater extent) and diltiazem was as effective as before. EDTA could not markedly prevent the degradative phenomenon caused by PHZ plus $\mathrm{Ca}^{2+}$.

Lipid peroxidation in biological membranes causes impairment of membrane function [18] decreases fluidity and inactivation of membrane bound enzymes and receptors [19]. In most cases haemoglobin acts as the catalyst for lipid peroxidation [4] and the erythrocyte membrane becomes an important target for damage [20]. Superoxide and hydroxyl radical might participate in PHZinduced toxicity [2]. Administration of PHZ to animals can induce peroxidative lipid damage of erythrocyte membrane resulting in the accumulation of MDA [21]. Many toxicants like PHZ induce hemolysis by the alteration of cytoskeletal protein [22]. Further detailed examination is necessary to clarify the mechanism of action of PHZ. Results from the present experiments suggest that selecting erythrocyte, as an in vitro model, could be used to ascertain the mechanism of haemolytic anaemia and prevention by calcium channel blocker which could act as antioxidant.

\section{ACKNOWLEDGEMENTS}

Thanks are due to the Council of Scientific and Industrial Research (CSIR), New Delhi, for the award of a research fellowship to Kaushik Das. We also acknowledge Late Dr. Asoke G Datta for his valuable advice and constructive criticism till the last moment of his life.

\section{REFERENCES}

[1] Biswas, S., Bhattacharyya, J. and Datta, A.G. (2005) Oxidant induced injury of erythrocyte-role of green tea leaf and ascorbic acid. Molecular and Cellular Biochemistry, 276(1-2), 205-210.

[2] Latunde-Dada, G.O., Vulpe, C.D., Anderson, G.J., Simpson, R.J. and McKie, A.T. (2004) Tissue-specific changes in iron metabolism genes in mice following phenylhydrazine-induced haemolysis. Biochimica et Biophysica Acta, 1690(2), 169-176.

[3] Halder, J. and Bhaduri, A.N. (1998) Protective role of bla- ck tea against oxidative damage of human red blood cells. Biochem. Biophysical Research Communications, 244(3), 903-907.

[4] Shetlar, M.D. and Hill, H.A. (1985) Reactions of hemoglobin with phenylhydrazine: A review of selected aspects. Environmental Health Perspectives, 64, 265-281.

[5] Bhattacharyya, J., Thompson, K.D. and Sayeed, M.M. (1993) Skeletal muscle $\mathrm{Ca}^{2+}$ flux and catabolic response during sepsis. American Journal of Physiology, 265(3), 487-493.

[6] Braughler, J.M., Dyncan, L.A. and Goodman, T. (1985) Calcium enhances in vitro free radical induced damage to brain synaptosomes mitochondria and cultured spinal cord neurons. Journal of Neurochemistry, 45(4), 12881293.

[7] Lu, C., Chan, S.L., Fu, W. and Mattson, M.P. (2002) The lipid peroxidation product 4-Hydroxyneal facilitates opening of voltage dependent $\mathrm{Ca}^{2+}$ channels in neurons by increasing protein tyrosine phosphorylation. Journal of Biological Chemistry, 277(27), 24368-24375.

[8] Buege, J.A. and Aust, S.D. (1978) Microsomal lipid peroxidation. Methods in Enzymology, 52, 302-310.

[9] Zhang, A., Zhu, Q.Y., Luk, Y.S., Ho, K.Y., Fung, K.P. and Chen, Z.Y. (1997) Inhibitory effect of jasmine green tea epicatechin isomers on free radical induced lysis of red blood cells. Life Sciences, 61(4), 383-394.

[10] Owens, C.W. and Belcher, R.V. (1965) A colorimetric micro-method for the determination of glutathione. Biochemical Journal, 94(3), 705-711.

[11] Bradford, M.M. (1976) A rapid and sensitive method for the quantitation of microgram quantities of protein utilizing the principle of protein-dye binding. Analytical Biochemistry, 72, 248-254.

[12] Williamson, P., Puchulu, E., Westerman, M. and Schlegel, R.A. (1990) Erythrocyte membrane abnormalities in sickle cell disease. Biotechnology and Applied Biochemistry, 12(5), 523-528.

[13] Nash, G.B., Boghossian, S., Parmar, J., Dormandy, J.A. and Bevan, D. (1989) Alteration of the mechanical properties of sickle cells by repetitive deoxygenation: role of calcium and the effects of calcium blockers. Journal of British Society of Haematology, 72(2), 260-264.

[14] Ohnishi, S.T., Horiuchi, K.Y., Horiuchi, K., Jurman, M.E. and Sadanaga, K.K. (1986) Nitrendipine, nifedipine, and verapamil inhibit the in vitro formation of irreversibly sickled cells. Pharmacology, 32(5), 248-256.

[15] Rojstaczer, N. and Triggle, D.J. (1994) Calcium channel antagonists as antioxidants. Cardiovascular Drug Reviews, 12(1), 70-84.

[16] Mason, R.P., Mak, I.T., Trumbore, M.W. and Mason, P.E. (1999) Antioxidant properties of Ca antagonists related to membrane biophysical interactions. American Journal of Cardiology, 84(4A), 16-22.

[17] Chowdhury, T.D., Das, N., Chattopadhyay, A. and Datta, A.G. (1999) Effect of oxidative stress and erythropoietin on cytoskeletal protein and lipid organization in human erythrocytes. Polish Journal of Pharmacology \& Pharmacy, 51(4), 341-350.

[18] Gutteridge, J.M. and Halliwell, B. (1990) The measurement and mechanism of lipid peroxidation in biological systems. Trends in Biochemical Sciences, 15(4), 129135. 
[19] Watanabe, H., Kobayashi, A., Yamamoto, T., Suzuki, S., Hayashi, H. and Yamazaki, N. (1990) Alterations of human erythrocyte membrane fluidity by oxygen-derived free radicals and calcium. Free Radical Biology and Medicine, 8(6), 507-514.

[20] Deuticke, B., Heller, K.B. and Haest, C.W.M. (1987) Progressive oxidative membrane damage in erythrocytes afterpulse treatment with t-butyl-hydroperoxide. Biochimica et Biophysica Acta, 899(1), 113-124.

[21] Jain, S.K. (1985) In vivo externalization of phosphati- dylserine and phosphatidylethanolamine in the membrane bilayer and hyper-coagulability by the lipid peroxidation of erythrocytes in rats. Journal of Clinical Investigation, 76(1), 281-286.

[22] Zachary, S.B., Jason, D.M., David, J.J. and David, C.M. (2005) Primaquine-induced hemolytic anaemia: role of membrane lipid peroxidation and cytoskeletal protein alterations in the hemotoxicityof 5-hydroxyprimaquine. Journal of Pharmacology and Experimental Therapeutics, 314(2), 838-845. 